\title{
CONCEPT DEVELOPMENT PROCESS FOR DOORS OF AUTONOMOUS VEHICLES
}

\author{
König, Adrian (1); \\ Neuhaus, Patrick (1); \\ Alexander, Koch (1); \\ Ferdinand, Schockenhoff (1); \\ Philipp, Hafemann (1); \\ Ingrid, Bubb (2); \\ Markus, Lienkamp (1) \\ 1: Institute of Automotive Technology, Technical University of Munich; \\ 2: Chair of Ergonomics, Technical University of Munich
}

\begin{abstract}
Vehicle doors have barely changed in recent decades, and nor has the car. Since autonomous driving will lead to changes in vehicles and how they are used, their doors will also have to be rethought. In the project UNICARagil, researchers from several universities in Germany design and build four prototypes of driverless and autonomous vehicles, which are developed based on a new and modular architecture. As part of this, we developed a concept including a prototype of an automated door system. In this paper, we present our concept development process adapted for door systems of autonomous vehicles. Based on the vehicle concept development process, it should help researchers and engineers to select and design new door concepts in an early phase. At the end, by means of an example, we present the prototype of our door concept as well as a boarding user study we carried out. This study helps evaluate and improve the boarding comfort of future door concepts.
\end{abstract}

Keywords: Autonomous Driving, vehicle doors, Computer Aided Design (CAD), Design methodology, Early design phases

\section{Contact:}

König, Adrian

Technical University of Munich

Mechanical Engineering, Institute of Automotive Technology

Germany

adrian.koenig@ftm.mw.tum.de 


\section{INTRODUCTION}

The doors on passenger cars are one component that has only changed slightly over the years. The type of kinematic has also remained the same for most cars. Passengers take car doors for granted, and use them 10,000 to 50,000 times over a lifetime (Morello et al. 2011, p. 325). With autonomous driving, the usage of passenger vehicles will probably change (Peters et al. 2019, p. 541). If a vehicle is designed to pick up passengers and drive them automatically to their destination, the door system has to be changed, too. Since there is no driver to help passengers get into the car, automatic door operation similar to buses and trains is required. Furthermore, modular and scalable solutions have to be developed to keep costs low, despite the trend towards individualization. Therefore, a process is needed to support the development of door concepts for passenger cars.

\section{STATE OF THE ART}

In the project UNICARagil, presented in Chapter 2.1, we develop a concept of an automatic door system for four autonomous prototypes. In doing so, we analyze the vehicle concept development process (Chapter 2.2) to adapt it for the door development and collect suitable door concepts (Chapter 2.3). Finally, we analyze existing literature about the comfort assessment of boarding (Chapter 2.4), which helps us to further improve the concept, before we present our methodology and results.

\subsection{Autonomous Vehicles in the UNICARagil Project}

Advancing technology readiness and the trend towards a sharing economy will change the future of mobility and transportation (Schröder and Gotzler 2021). Fully autonomous vehicles are expected to boost car and ride sharing services. Considering this development, new vehicle architectures are necessary that meet the requirements of these new modes of transportation. Within the research project UNICARagil, a consortium of seven universities and six industrial partners aims to develop disruptive and modular architectures for future autonomous vehicles (Woopen et al. 2018). To demonstrate the resulting architectures, four autonomous prototype vehicles are realized. Each prototype vehicle represents a different use case of future transportation. The four prototype vehicles are:

1. autoTAXI, a taxi for private or business trips

2. autoELF, a privately-owned vehicle that supports families in their daily mobility needs

3. autoCARGO, a mobile package delivery station that can pick up and deliver parcels

4. autoSHUTTLE, a public transport vehicle that transports small groups of people

The prototype vehicles are built in line with a modular and scalable approach in terms of hardware and software. As shown by Böddeker (2019), the vehicles' exterior design is based on a modular platform that allows for the use of structural extension pieces to realize different vehicle lengths and heights. Using this approach, two vehicle sizes are realized; autoTAXI and autoELF share the smaller platform variant, whereas autoCARGO and autoSHUTTLE are built on the larger platform variant. The modular approach requires existing components to be reused, independent of the vehicle size. Therefore, one special focus of the research is the door concept that should be developed in a modular way to fit all four prototype vehicles.

\subsection{Vehicle Concept Development Process}

Nicoletti et al. (2020) describe the vehicle concept development process in four main steps. First, the customer-relevant properties are defined. They describe the requirements from the customer's point of view, as she/he should buy the resulting vehicle. The second step is the selection and dimensioning of components to fulfill these customer-relevant properties. Third, the vehicle concept merges all components by locating them with dimensional chains. As a result, the entire vehicle concept is created and the concept engineer can focus on the dependencies between the components. The final step is a comparison of the required customer-relevant properties and the designed vehicle concept. Since there are different interdependencies, e.g. in the vehicle weight, a series of iteration loops must be performed. Traditionally, a portfolio of many customer-relevant properties is available, focusing on e.g. driving experience, design or comfort (Ziemann 2006, pp. 138-153). Schockenhoff et al. (2020) have researched these customer-relevant properties of autonomous vehicle concepts and identified new important aspects from the customer's point of view. Among other aspects, boarding will become a 
significant part of the user experience with the vehicle. The entering and exiting process will change with different interior topologies, like vis- à -vis and various mobility concepts like ridesharing.

\subsection{Door Concepts}

Door concepts on passenger cars currently consist of simple, manual doors. There are many ways to attach a door to the vehicle and move it. These numerous possibilities are often classified depending on the kinematic door type (Morello et al. 2011, p. 326). We take four common door types used in current vehicles and concept cars (Figure 1). Most cars today are equipped with conventional doors in both the front and rear. Only large, high-capacity vehicles such as vans and minivans often have sliding doors for the rear row. Conventional doors are mounted at the height of the A-pillar (front door) or B-pillar (rear door). If a conventional front (rear) door is mounted at the height of the B- (C-) pillar, so that the door opens to the rear, it is called a suicide door.

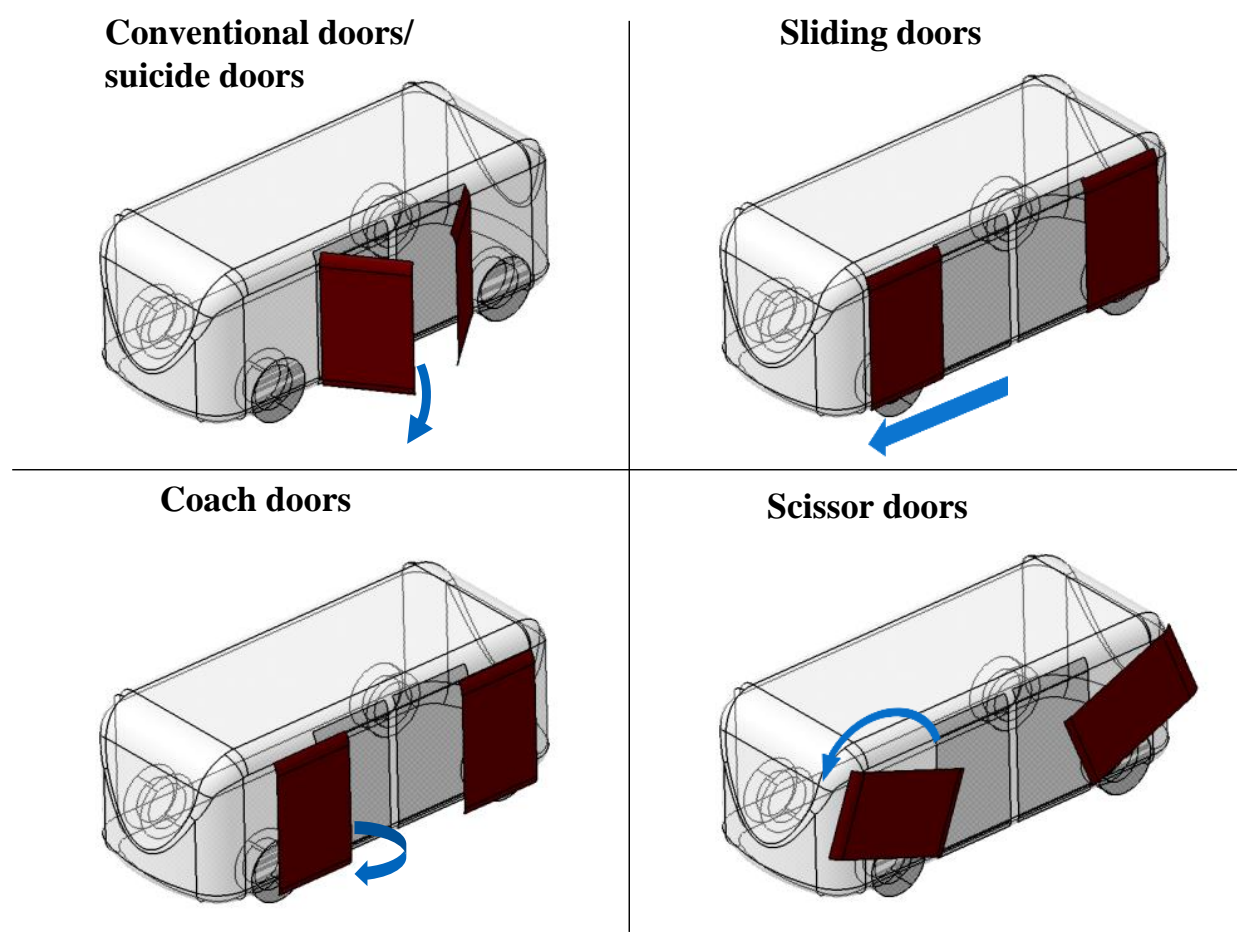

Figure 1. Common door concepts for passenger vehicles

Sliding doors and coach doors are typically used in trains or buses, and open and close automatically, unlike current passenger cars. Scissor doors usually only be found in sport cars.

\subsection{Comfort Assessment of Boarding}

For the boarding comfort rating, user studies link objective dimensions with the subjective perception of comfort. Several studies can be found in literature, focusing on the entrance.

Petzäll's (1995) research focuses on an optimized vehicle design of the passenger door area to make entering and exiting easier for elderly and disabled passengers. He uses a mock-up with adjustable door opening width and height, sill height, door opening angle and seating position to specify ideal values for these dimensions. The rating is taken from a measurement of the time needed to perform the task. The study is one of the first to investigate these motions.

Causse et al. (2012), Fischer et al. (2008) and Sabbah (2010) use similar approaches in their experiments. They try to find ergonomically ideal values for vehicle dimensions, such as seating height above the ground (H30), roof height (H50) and the sill width and height (H115) with adjustable mock-ups. The discomfort rating is based on the CP-50 scale, which is sometimes slightly modified or supplemented with an interview. Rigel (2005) also uses an adjustable mock-up to gather data for developing a discomfort model for entering and exiting motions. The rating is determined by a specially designed questionnaire. 
Chatteauroux and Wang's (2010) experiment focuses on the exit motion. Based on earlier experiments conducted by Petzäll, as well as Giacomin and Quattrocolo (1997), they identify the door opening width and height, the sill height and the seating position as the most crucial dimensions for the exit. They generate data using motion tracking and by rating the exit from different production cars on a visual analog scale. Bodenmiller et al. (2002) use production cars for their experiments. They determine the level of discomfort from an interview. When bodies of production cars are used, it is not possible to vary dimensions. Besides Petzäll and Giacomin, all authors focus on the driver. Therefore, the steering wheel takes up a considerable part of the area in which the motions are performed.

Wasser et al. (Wasser et al. 2018) conduct an ergonomic evaluation with a mock-up of an autonomous car. They use a questionnaire to collect data, but they do not include boarding.

\subsection{Research Gap}

Barely any research work can be found in the field of door concept development. One possible reason for this is the use case of passenger cars, which has almost not changed over the past decades (private person buying a manually driven car) and led to an unchanged door concept. Consequently, the existing research in the area of doors deals with improving properties of the existing concept (e.g. aeroacoustics and weight) (VDI 2019) and not with the search for new concepts.

However, autonomous driving will change the use of passenger cars according to literature (Peters et al. 2019, p. 541). Consequently, the door concept has to be adapted to these changing use cases. Since there are a lot of possible ways of designing a door concept, we created a process similar to the vehicle concept development to help researchers and developers in the selection and design of new door concepts. Furthermore, although numerous studies are available that rate the entering and exiting motions in cars in a scenario with a conventional door concept, there are no known experiments that focus on alternative door systems for an automotive application. Therefore, we present results from our user study, which helps to assess and improve the comfort of a door concept.

\section{METHODOLOGY}

Because the door system is an individual subsystem of a vehicle, in this chapter we present our methodology designed specifically for door concept development.

\subsection{Development Process of Door System}

While developing the door concept, we were guided by the vehicle concept development process (Nicoletti et al. 2020) and adapted it for the door development (Figure 2).

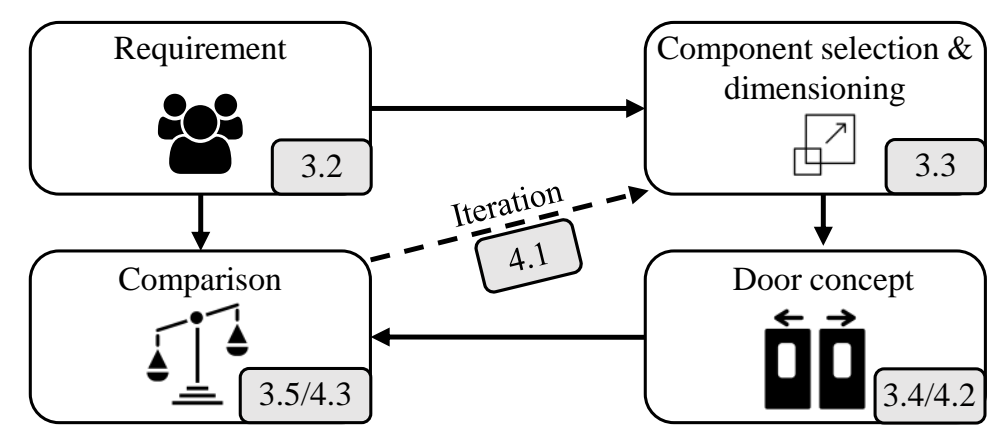

Figure 2. Development process of door concept based on vehicle concept development process (Nicoletti et al. 2020)

Starting with the definition of the requirements (Chapter 3.2), we first selected and dimensioned all the components needed (Chapter 3.3). After placing the components in the available package space (Chapter 3.4), we compared the properties achieved by different door concepts with the requirements (3.5). In the following chapters, we present the results achieved after improving the concept during iteration loops (Chapter 4.1 and 4.2) and a comparison between requirement and resulting property using the example of boarding comfort (Chapter 4.3).

\subsection{Requirements}

We define the following categories of requirements for the door system: 
- $\quad$ Costs (price of development, components and production)

- Comfort (comfort during opening/closing and boarding)

- $\quad$ Safety (emergency exit and anti-pitch protection)

- Design (influence on the vehicle design)

Costs include not only the component and production costs, but also costs due to more complex development. Using scalable solutions and modular subsystems can help reduce costs and development times. Comfort includes ergonomic requirements and standards, as well as required maximum and minimum dimensions. Safety includes misuse on the one hand and safety during operation on the other. Design is related in particular to the complete vehicle and whether the door influences it.

To meet comfort requirements in the best possible way, a user-centered approach must be taken. Comfort and well-being will be key factors for the user's acceptance of autonomous driving (Kipp et al. 2020) (Schockenhoff et al. 2020). In the scope of the paper, we focus on the comfort during the ingress but also boarding time and air conditioning are aspects of comfort related to the door concept. However, this could only be pursed to a certain extent, because the vehicle build package in UNICARagil was fixed after only six months, due to a short development time. Due to an underfloor battery and the required ground clearance of $120 \mathrm{~mm}$, the sill height is $340 \mathrm{~mm}$. This corresponds to the usual sill height of a bus (Reinhardt 2012, p. 330) as well as the usual H115 sill heights of conventional vehicles (Bichler 2015).

Unlike with a conventional vehicle, the passenger does not have to cross the sill but must climb on it, similar to a staircase (Figure 3). This will result in a different movement behavior by vehicle users. For conventional cars, boarding strategies like "slipping" or "fiddling" (Bubb 2015, 435ff) cannot typically be realized. This effect is further enhanced by the demand for a variable interior configuration.

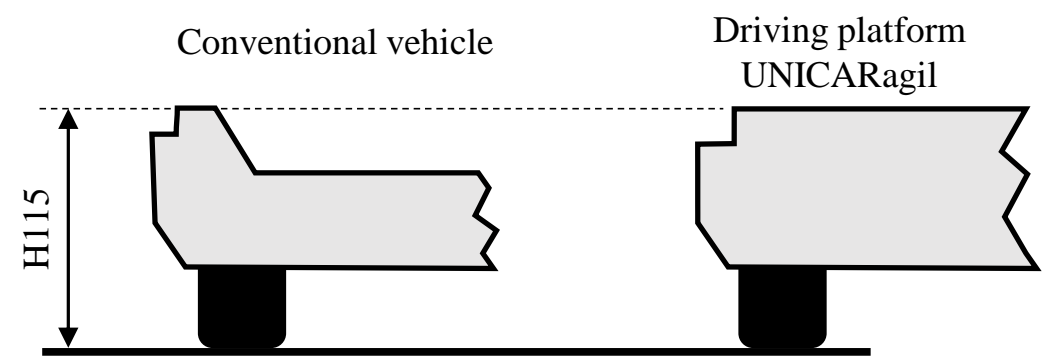

Figure 3. Driving platform of UNICARagil compared to conventional vehicle

Due to the lack of literature and our own experience with these new boundary conditions, we first assumed an interior height of $1,800 \mathrm{~mm}$, because this height allows a man in the 95th percentile to enter in a slightly stooped position. We will evaluate this assumption in the results (Chapter 4.3).

Table 3 sums up the requirements in the development of the UNICARagil door. We therefor combined the specification for the complete vehicles from the project with requirements on automatic door systems.

Table 3. Requirements for door system in the UNICARagil project

\begin{tabular}{ll}
\hline Costs & - Low complexity \\
& - Modularization (as many parts for both vehicle sizes) \\
& - Scalability (scaling parts instead of reconstruction) \\
\hline Comfort & $-1,500 \mathrm{~mm}$ (small vehicle)/2,000 mm (large vehicle) boarding width \\
& - Min. $1,800 \mathrm{~mm}$ interior height for boarding \\
& - Low swing-out movement during door opening \\
\hline Safety & - Mechanical safety during minimal misuse (person leaning against door) \\
& - Basic anti-pinch protection between doors \\
\hline Design & - No/little influence on exterior design \\
\hline
\end{tabular}




\subsection{Component Selection and Dimensioning}

The choice of suitable components and the way in which they are placed in the available space defines the door concept and influences its properties. We considered the following components for a possible door system: sliding mechanism, rotating mechanism, locking mechanism, door structure (including door panel), HMI (display and control element), windows, sensors, wiring harness and sealing. The selection of a door kinematic principle opens a selection of further subcomponents. For instance, the selection of the sliding mechanism allows the following options for driving the linear guide:

- $\quad$ Rack

- Wire winch

- Worm gear

- Hydraulic/pneumatic piston

Once the components have been selected, they have to be dimensioned for the normal load case. Depending on the kinematic, the load case has to be divided into partial loads for each component. Where possible, we already considered interactions between components. For example, the number of latches and actuators selected also determines the number of connections to the control unit.

In the large vehicles, the requirement of an interior height of $1,800 \mathrm{~mm}$ was fulfilled, in the small vehicles only a level of $1,500 \mathrm{~mm}$ was reached due to design and technical requirements. To ensure that this requirement was still met, the roof of the smaller vehicles had to be designed so that it could be opened.

\subsection{Door Concept}

After selecting and dimensioning components, we mount them together in a given package space. The result is the door concept, which includes the position and size of every component. Spatial conflicts normally arise in this process step if the given package space does not allow all components to be placed. Furthermore, functional interdependencies may come up that must be taken into account. A kinematic simulation in the CAD environment also helps detect possible dynamic collisions.

\subsection{Comparison}

In the last step of the methodology, we determine the properties of the first draft of the door concept and compare them to the requirements. If several properties from the requirement are violated, a weighting discussed with all project partners helps find the best compromise. Besides weighing up the advantages and disadvantages of concepts, we use several methods for the comparison, depending on the property. User studies support the evaluation of the boarding comfort, CAD and FEM investigations help evaluate the technical suitability of different concepts.

\section{RESULTS}

In the following chapters, we present the first testing results and the manufactured door prototype. We show the final selection of components and a user study testing the boarding comfort. The complete vehicles including the door system will be presented in the final presentation in the year 2022.

\subsection{Iterations of the Concept Development}

By way of example, we describe the selection of a suitable kinematic concept to demonstrate the importance of iteration loops. Therefore, we evaluated the four concepts shown in Figure 1 for the use cases in UNICARagil. Once a first draft of the four possible concepts had been created, we evaluated them in order to improve only one version in the following iteration loops. Therefore, we checked which concept has a positive and negative influence on the fulfillment of the requirements (Table 3 ). We have also evaluated those concepts with kinematic simulations, but do not describe those details within the scope of this paper.

Every concept mentioned has negative influences on the fulfillment of the requirements. Therefore, we decided to use a combination of the sliding and coach mechanism to overcome the disadvantages of each concept. If the rails of the sliding mechanism are moved to the door side, they are not visible from the outside and no longer have a negative effect on the exterior design. 
Table 3. Comparison of door concepts

\begin{tabular}{lllll}
$\begin{array}{l}\text { Door } \\
\text { concept }\end{array}$ & $\begin{array}{l}\text { Conventional/ } \\
\text { suicide }\end{array}$ & Sliding & Coach & Scissor \\
\hline $\begin{array}{l}\text { Positive } \\
\text { influence }\end{array}$ & $\begin{array}{l}+ \text { Costs (simple) } \\
+ \text { Costs (scalable) }\end{array}$ & $\begin{array}{l}\text { + Comfort } \\
\text { + Costs (scalable) }\end{array}$ & + Costs (scalable) & + Comfort \\
$\begin{array}{l}\text { Negative } \\
\text { influence }\end{array}$ & - Comfort & - Design & - Comfort & - Safety
\end{tabular}

Using a four-linkage mechanism with shorter arms no longer affects comfort because the swing-out movement during opening is low. Lastly, we achieved the modularity by using the same components for the four-linkage mechanism, and the scalability by using different rail lengths for the linear mechanism. Similar to the shown example, other components such as the locking system were also iteratively selected and improved.

\subsection{Door Concept}

The final door concept is the result of several iteration loops during the development process. It consists of two doors for each openable vehicle side with an openable roof structure for the smaller vehicle platform (Figure 4). The door's opening mechanism is a four-linkage rotating mechanism in combination with a sliding mechanism.

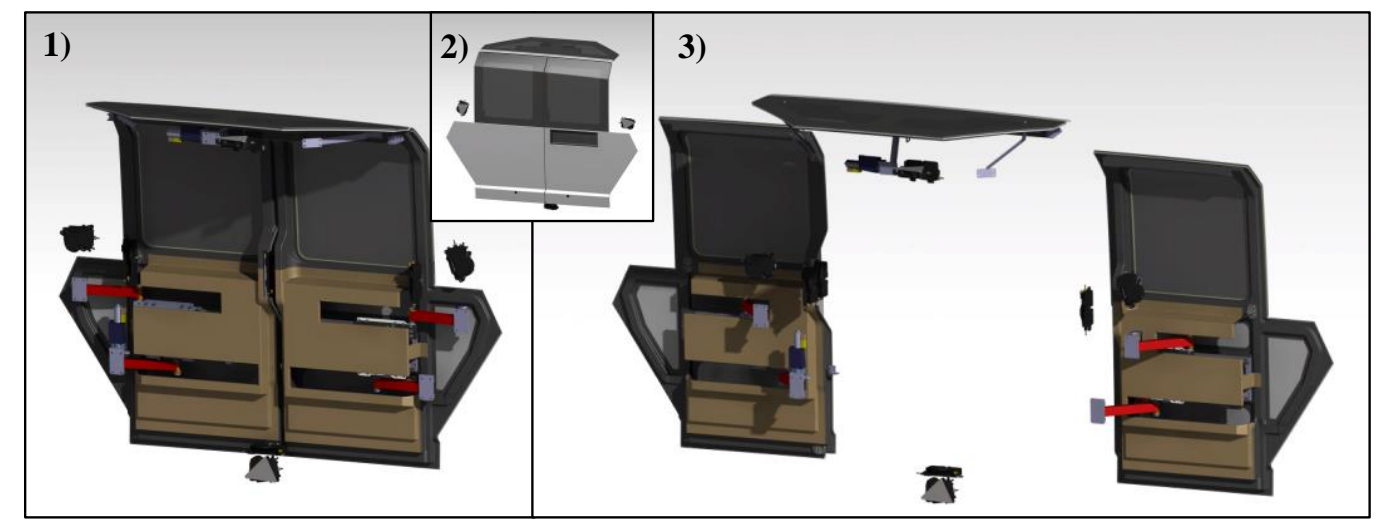

Figure 4. Door concept including roof opening. 1) Closed - inside view 2) Closed - outside view 3) Opened - inside view

First, the four-linkage rotates the door (on the right side of Figure 5). Here, the theoretical maximum boarding width of one door is twice the length of the four-linkage's length. Thus, a mechanical conflict arises between maximum boarding width and swing-out movement. The sliding mechanism (in the middle of Figure 5) resolves the conflict, as it creates additional boarding width without increasing swing-out movement.

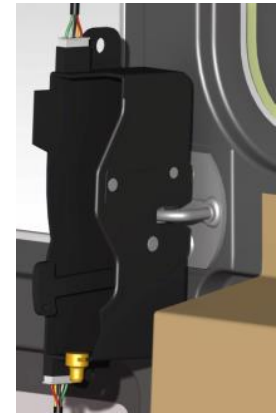

Locking mechanism

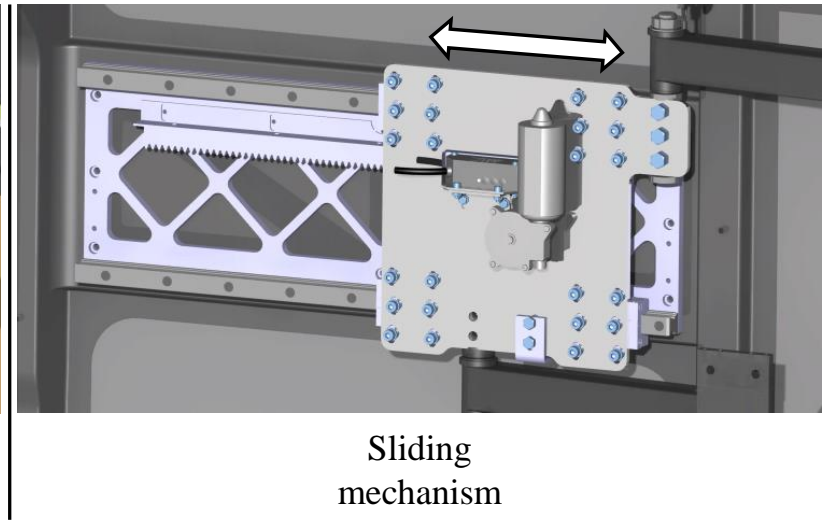
mechanism

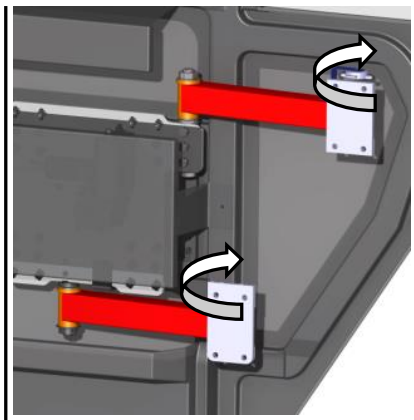

Four-linkage mechanism

Figure 5. Subsystems of door concept 
With rails integrated in the door, no rail has to be attached at the vehicle's outer contour. Since the four-linkage represents the interface between door and vehicle and cannot be purchased in a modular format, it was developed within the project. However, sliding mechanisms can be purchased and are easily scalable to the rail's length. Thus, the four-link mechanism is the same for both platforms, while different rail lengths achieve the scaling in boarding width. The roof mechanism is a four-linkage, moving the roof upwards. This ensures protection from the weather when the roof is opened.

The locking system (left side of Figure 5) consists of five latches with soft-close function for each vehicle side. If the roof is openable, an additional latch with soft-close function is used. The soft-close feature is used to ensure function and safety. On the one hand, the latches hold the closed door in place. On the other hand, they allow safer closing. Due to the door's dimensions, the resulting sealing force is high. To overcome the force without potentially dangerous high door momentum, the soft close function is used.

The dimensioning of the four-linkage's arms and the rail's length is a typical problem in the component selection and dimensioning process. However, the resulting opening width depends on the overall door concept, including the package. The width depends on the start and end angle of the four-linkage, the rail's free travel and other subsystems, such as the locking mechanism. Since the locking system requires a latch between the doors, the two doors need to overlap each oth+er. However, this dimension must be overcome by a wider kinematic opening. Thus, the development process of a door concept is highly iterative.

\subsection{Comparison in Boarding Comfort}

Since we did not find a suitable study to evaluate the boarding comfort, a user study is carried out to determine the comfort and investigate how varying certain vehicle dimensions affects boarding from an ergonomic point of view. Fourteen participants with body size between $159 \mathrm{~cm}$ and $192 \mathrm{~cm}$ rate their discomfort during the motion on a CP50 scale, for every configuration. We use discomfort instead of comfort, since the literature above shows that the reduction of discomfort is a suitable method to improve boarding comfort. The design of the autoTAXI is used as a baseline and recreated in a mock-up. The parameters that we varied are the door opening width, the sill height H115 and the option of having a roof opening to enable an upright standing position in the vehicle. A closed roof results in a roof height $\mathrm{H} 50$ of $1,850 \mathrm{~mm}$ from the ground for the baseline. The different configurations and their measurements are shown in Table 4.

Table 4. Design configurations in the discomfort study

\begin{tabular}{llll} 
Configuration & Sill height in $\mathbf{~ m m}$ & Roof open/closed & Door opening width in $\mathbf{~ m m}$ \\
\hline Baseline & 360 & Open & 1,370 \\
1 & 360 & Open & 770 \\
2 & 250 & Open & 1,370 \\
3 & 160 & Open & 1,370 \\
4 & 360 & Closed & 1,370 \\
5 & 250 & Closed & 1,370 \\
6 & 160 & Closed & 1,370
\end{tabular}

Figure 6a visualizes the data of the entry as a box-plot-chart. The interquartile range of all configurations with an open roof are in an area of low or very low discomfort. The smaller door opening width of configuration 1 reduces discomfort in comparison to the baseline. Configuration 2 with a sill height of $250 \mathrm{~mm}$ is found to be the best design for the entry motion. The even lower sill of configuration 3 results in greater discomfort for the test persons. Both variations have average values in the section of very low discomfort. The configurations with a closed roof show a broad range of ratings from very low to very high discomfort. The averages are considerably higher than the corresponding variants with open roof. Configuration 6 causes the highest discomfort.

The results of the exit are presented in Figure $6 \mathrm{~b}$ as a box-plot-chart. Compared to the baseline, the narrower door opening width of configuration 1 does not significantly increase discomfort. The average is the same. For the exit motion, the lowest sill causes the least discomfort. Configuration 2 is still a good improvement from the baseline. Similar to the entry, the examination of the versions with 
a closed roof show an optimum for the sill height of $250 \mathrm{~mm}$. Overall, the test persons felt less discomfort during the exit motion.

The data collected in the study shows that the sill and roof height cannot be considered separately as they affect each other. The greatest increase in comfort is generated through the ability to have an upright body position in the car. A low sill height can make it easier to get in and out of the car, even more so with sufficient roof height. Unfortunately, the sill height is defined by the boundary conditions of other project partners, but could be improved in the future. The study shows no considerable benefit for a passenger car with the larger door opening width. Consequently, both doors should be opened only when needed, otherwise conditioned air is lost, with no benefit.

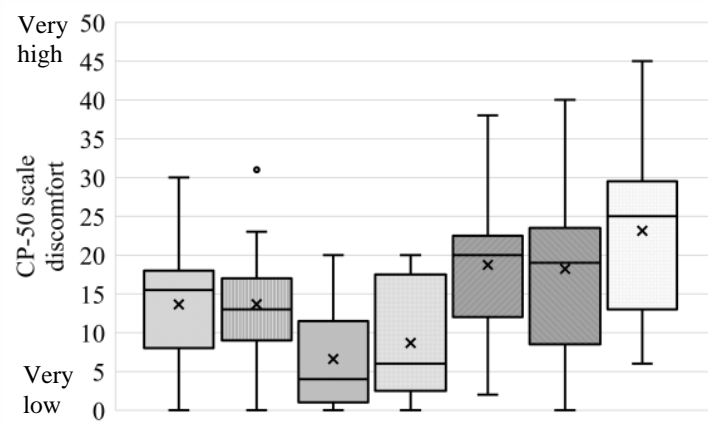

a)

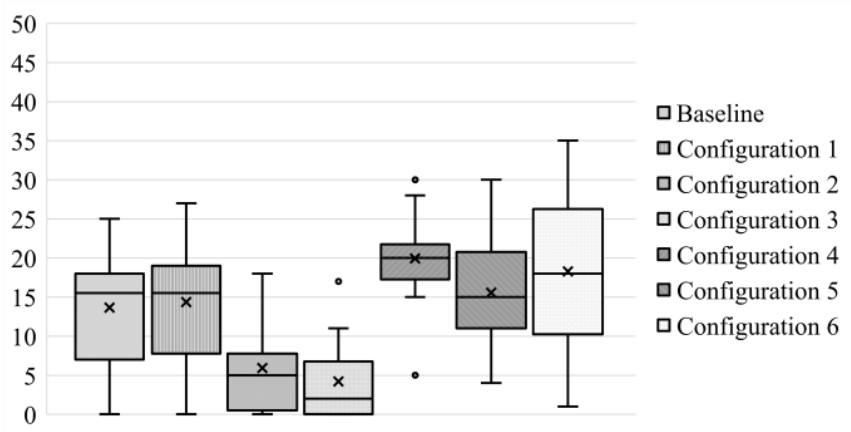

b)

Figure 6. Discomfort rating of the a) entry motion and b) exit motion

\section{DISCUSSION AND OUTLOOK}

Our methodology presented in this paper aims to help engineers in the early development of boarding systems. Starting with simple properties, our methodology accompanies the complete boarding concept development process. Since we only build up prototypes during the UNICARagil project, the methodology has to be extended further for the development of series production cars. Important boundary conditions like obligatory standards or regulations have to be added in the future. Since the methodology needs several iteration loops, it still has potential in terms of efficiency.

The door concept resulting from our methodology meets requirements well. Further improvement can be achieved by a lower sill height, but this cannot be realized in the project due to fixed boundary conditions. Since the door width barely influences discomfort, it could be reduced in a series production car to save cost. This would also increase the comfort related to air conditioning because the loss of cooled or heated air during opening is reduced.

Furthermore, more ergonomic research is needed for new door concepts to support their selection and evaluation. We were only able to carry out our studies with 14 participants, all of whom were in good health. Further studies should include more participants and, in particular, physically limited and older people, since autonomous driving holds the biggest potential for them.

In the future, we will proceed with further research focusing on interactions between boarding and vehicle operation. In addition, more testing on the final vehicle prototype is needed to further improve the hardware.

\section{ACKNOWLEDGMENTS}

This research is accomplished within the project "UNICARagil" (FKZ EM2ADIS002). We acknowledge financial support for the project by the Federal Ministry of Education and Research of Germany (BMBF).

\section{REFERENCES}

Bichler, R. J. (2015): Biomechanik und Fahrzeugentwicklung: Erstellung und Anwendung eines Modells zur virtuellen Beurteilung des Ein- und Ausstiegs. Disseration. Technical University of Munich, München.

Böddeker, Torben (2019): Tailored for Automation - Purpose Design for Autonomous Urban Mobility in UNICARagil. In ATZ live (Ed.): Vehicles of Tomorrow 2019. Concept-Materials-Design. Vehicles of Tomorrow 2019. Frankfurt am Main, Germany. 
Bodenmiller, Faith M.; Hart, James M.; Bhise, Vivek D. (2002): Effect of Vehicle Body Style on Vehicle Entry/Exit Performance and Preferences of Older and Younger Drivers. In : SAE Technical Paper Series. SAE 2002 World Congress \& Exhibition, MAR. 04, 2002: SAE International400 Commonwealth Drive, Warrendale, PA, United States (SAE Technical Paper Series).

Bubb, Heiner (2015): Automobilergonomie. Wiesbaden: Springer Vieweg (ATZ / MTZ-Fachbuch).

Causse, Julien; Wang, Xuguang; Denninger, Lisa (2012): An experimental investigation on the requirement of roof height and sill width for car ingress and egress. In Ergonomics 55 (12), pp. 1596-1611. https://dx.doi.org/10.1080/00140139.2012.722694.

Chateauroux, Elodie; Wang, Xuguang (2010): Car egress analysis of younger and older drivers for motion simulation. In Applied ergonomics 42 (1), pp. 169-177. https://dx.doi.org/10.1016/j.apergo.2010.07.001.

Fischer, Markus; Richter, C. E.; Braun, S.; Hellenbrand, David; Sabbah, Olaf; Scharfenberger, Christian et al. (2008): Multidisciplinary Development of New Door and Seat Concepts as Part of an Ergonomic Ingress/Egress Support System. In Proceedings of the FISITA 2008 World Automotive Congress. Available online at https://www.semanticscholar.org/paper/Multidisciplinary-Development-of-New-Door-and-SeatFischer-Richter/e9d06cd357ae6e8300fdc34aab9f9208b1d3d6cb.

Giacomin, J.; Quattrocolo, S. (1997): An analysis of human comfort when entering and exiting the rear seat of an automobile. In Applied ergonomics 28 (5-6), pp. 397-406. https://dx.doi.org/10.1016/S00036870(97)00001-X.

Kipp, Manuel; Bubb, Ingrid; Schwiebacher, Johannes; Schockenhoff, Ferdinand; Koenig, Adrian; Bengler, Klaus (2020): Requirements for an Autonomous Taxi and a Resulting Interior Concept. In Constantine Stephanidis, Margherita Antona (Eds.): HCI International 2020 - Posters, vol. 1226. Cham: Springer International Publishing (Communications in Computer and Information Science), pp. 374-381.

Morello, Lorenzo.; Rossini, Lorenzo Rosti.; Pia, Giuseppe.; Tonoli, Andrea. (2011): The Automotive Body. Volume I: Components Design. Dordrecht: Springer; Springer Netherlands; Imprint (Mechanical Engineering Series, 0).

Nicoletti, Lorenzo; Brönner, Matthias; Danquah, Benedikt; Koch, Alexander; König, Adrian; Krapf, Sebastian et al. (2020): Review of Trends and Potentials in the Vehicle Concept Development Process. In 2020 Fifteenth International Conference on Ecological Vehicles and Renewable Energies (EVER). https://dx.doi.org/10.1109/EVER48776.2020.9243115.

Peters, Peter Lukas; Demuth, Rainer; Schramm, Dieter (2019): Evaluation of the effects of trends on vehicle concepts based on a forecast of travel demand. In Michael Bargende, Hans-Christian Reuss, Andreas Wagner, Jochen Wiedemann (Eds.): 19. Internationales Stuttgarter Symposium, vol. 122. Wiesbaden: Springer Fachmedien Wiesbaden (Proceedings), pp. 540-556.

Petzäll, Jan (1995): The design of entrances of taxis for elderly and disabled passengers. In Applied ergonomics 26 (5), pp. 343-352. https://dx.doi.org/10.1016/0003-6870(95)00051-8.

Reinhardt, Winfried (2012): Fahrzeuge im Öffentlichen Personennahverkehr. In Winfried Reinhardt (Ed.): Öffentlicher Personennahverkehr. Wiesbaden: Vieweg+Teubner Verlag, pp. 197-342.

Rigel, Stefan (2005): Entwicklung und Validierung einer Methode zur quantitativen Untersuchung der Ein- und Ausstiegsbewegung in einen Pkw. Dissertation. Technical University of Munich, Munich.

Sabbah, Adel Olaf (2010): Entwicklung eines dynamischen Diskomfortmodells am Beispiel des Ein- und Ausstiegs. Dissertation. Technical University of Munich, Munich.

Schockenhoff, Ferdinand; König, Adrian; Koch, Alexander; Lienkamp, Markus (2020): Customer-Relevant Properties of Autonomous Vehicle Concepts. In Procedia CIRP 91, pp. 55-60. https://dx.doi.org/10.1016/j.procir.2020.02.150.

Schröder, Daniel; Gotzler, Felix (2021): A holistic spatial and cost assessment of urban transport options in Munich. In Journal of Urban Mobility (submitted).

VDI (Ed.) (2019): OEM Forum Fahrzeugtüren und -klappen 2019. Bad Gögging, 26.-27. März 2019. OEM Forum Fahrzeugtüren und -klappen. Bad Gögging, 26.-27. März 2019. Düsseldorf: VDI Verlag (VDI-Berichte).

Wasser, Joscha; Diels, Cyriel; Baxendale, Anthony; Tovey, Michael (2018): Ergonomic Evaluation of a Driverless Pod Design. In Proceedings of the Human Factors and Ergonomics Society Annual Meeting 62 (1), pp. 1389-1393. https://dx.doi.org/10.1177/1541931218621317.

Woopen, Timo; Eckstein, Lutz; Kowalewski, Stefan; Moormann, Dieter; Maurer, Markus; Ernst, Rolf et al. (2018): UNICARagil - Disruptive modulare Architektur für agile, automatisierte Fahrzeugkonzepte. With assistance of Timo Woopen, Bastian Lampe, Torben Böddeker, Alexandru Kampmann, Bassam Alrifaee, Torben Stolte et al. In : 27. Aachen Colloquium Automobile and Engine Technology. 27. Aachen Colloquium Automobile and Engine Technology. Aachen, October 8th-10th.

Ziemann, Alexander (2006): Zielsystemmanagement für die Produktentstehung von PKW. Dissertation. Technical University of Munich, Munich. 